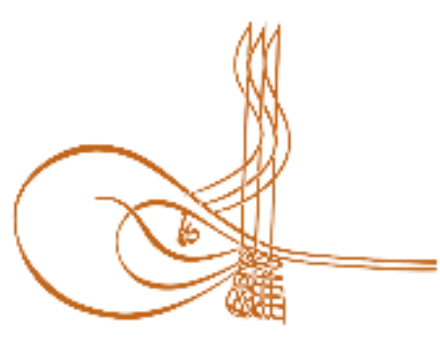

www.turkishstudies.net/social
Turkish Studies - Social Sciences

eISSN: $2667-5617$

Research Article / Araștırma Makalesi

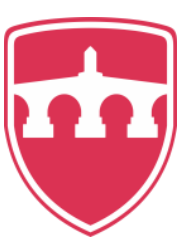

INTERNATIONAL BALKAN

UNIVERSITY Sponsored by IBU

\title{
Şehirlerarası Yolcu Taşımacılığında Hizmet Kalitesi, Davranışsal Niyet ve Memnuniyet İlişkisi: Çankırı Karatekin Üniversitesi Örneği
}

\author{
The Relationship Between Service Quality, Behavioral Intention and Satisfaction in Intercity \\ Passenger Transport: Sample of Çankırı Karatekin University
}

\author{
Hüseyin Özdemir ${ }^{*}$ - İrfan Mısırlı**
}

\begin{abstract}
In this research, it was investigated whether the perceived service quality, behavioral intention and satisfaction in the intercity bus companies show a significant difference according to the demographic characteristics of the students. In addition the relationship between perceived service quality, behavioral intention and satisfaction in intercity bus companies was investigated. The population of the research is the students studying at Çankırı Karatekin University and using them to intercity bus companies. The sample of the study was 424 students who accepted to participate in the study. In the research, questionnaire technique was used as data collection technique. The questionnaire consisted of two parts, in the first part questions were asked about the demographic characteristics of the students, in the second part, the service quality scale consisting of 5 dimensions (Service, service (transportation), personnel, responsiveness and security) and 28 statements to determine the quality of service, and 7 statements to determine the behavioral intentions of the students. five-point Likert-type scales were used to determine the general satisfaction of students. Duman, Ayduğan and Koçuk (2007), Yılmaz (2012), Koçoğlu and Aksoy (2012), Özdipçiner and Ceylan (2016) and Aliçavuşoğlu and Gürbüz (2017) were used in the preparation of the questionnaire. The statistical analysis of the questionnaire, which was answered by 424 students, was carried out with IBM SPSS 22 statistical package program. Frequency distribution, descriptive statistics, $T$ test, one-factor analysis of variance and correlation tests were used in the analysis of the data. Among the demographic variables examined, a statistically significant difference was found between the students' class and the general satisfaction of the students for bus companies. There was found between students' behavioral intentions and perceived service quality dimensions (Service, service (transportation), personnel, responsiveness and security) a positive, high, medium, medium, medium and medium relationship. There was a positive, weak, weak, weak, weak and
\end{abstract}

\footnotetext{
* Dr. Öğr. Üyesi, Çankırı Karatekin Üniversitesi, Ilgaz Turizm ve Otelcilik Yüksekokulu, Turizm İşletmeciliği ve Otelcilik Bölümü

Asst. Prof. Dr., Cankiri Karatekin University, Ilgaz School of Tourism and Hotel Management, Department of Tourism and Hotel Management

ORCID 0000-0002-9598-6938

huseyinozdemir@karatekin.edu.tr

** Dr. Öğr. Üyesi, Kastamonu Üniversitesi, Turizm Fakültesi, Turizm ve Otel İşletmeciliği Bölümü

Asst. Prof. Dr., Kastamonu University, Faculty of Tourism, Department of Tourism and Hotel Management

ORCID 0000-0001-9400-005X

imisirli@kastamonu.edu.tr

Cite as/ Atıf: Özdemir, H., Mısırlı İ. (2020). Şehirlerarası yolcu taşımacılığında hizmet kalitesi, davranışsal niyet ve memnuniyet ilişkisi: Çankırı Karatekin Üniversitesi örneği, Turkish Studies - Social, 15(2), 281-299. https://dx.doi.org/10.29228/TurkishStudies.40064

Received/Geliş: 08 December/Aralık 2019

Accepted/Kabul: 25 February/Şubat 2020

Copyright $($ INTAC LTD, Turkey

Checked by plagiarism software

Published/Yayın: 29 February/Şubat 2020

CC BY-NC 4.0
} 
weak relationship between students' general satisfaction and service quality dimensions (Service, service (transportation), personnel, responsiveness and security) and (positive) medium relationship between behavioral intentions and general satisfaction of students.

Structured Abstract: Introduction and Purpose: When the literature on service quality is analyzed, it is seen that the definitions made about service quality differ according to the service sector and the quality of the service provided. For a quality service, at least the level of service required to meet customer expectations is required. Satisfaction or dissatisfaction reasons, which are indicators of the satisfaction levels of the customers regarding the service quality, are seen as an important factor in the evaluation of the service quality. The intention of customers to choose a business and its products again and their positive thoughts about it is shaped by being influenced by issues such as the quality of service provided and customer satisfaction. In this research, it was investigated whether the perceived service quality, behavioral intention and satisfaction in the intercity bus companies show a significant difference according to the demographic characteristics of the students. In addition the relationship between perceived service quality, behavioral intention and satisfaction in intercity bus companies was investigated. In the research conducted, it was determined that the perception of service quality was determined by five basic factors: service, personnel, service (transportation), enthusiasm and security. For this purpose, the following hypotheses have been developed:

Hypothesis 1: Students' perception of service quality varies significantly difference according to their demographic characteristics (gender, age and in what grade)

Hypothesis 1a: Students' perception of service dimension significantly difference according to their demographic characteristics (gender, age and in what grade).

Hypothesis 1b: Students' perception of service (transportation) size significantly difference according to their demographic characteristics (gender, age and grade).

Hypothesis 1c: Students' perception of staff size varies significantly difference according to their demographic characteristics (gender, age and in what grade).

Hypothesis 1d: Students' perception of enthusiasm dimension significantly difference according to their demographic characteristics (gender, age and in what grade).

Hypothesis 1e: Students' perception of safety dimension varies significantly difference according to their demographic characteristics (gender, age and in what grade).

Hypothesis 2: The behavioral intentions of students significantly difference according to their demographic characteristics (gender, age and in what grade).

Hypothesis 3: Students' satisfaction significantly difference according to their demographic characteristics (gender, age and in what grade).

Hypothesis 4: There is a significant relationship between students' behavioral intentions and their perceptions of service quality.

Hypothesis 4a: There is a significant relationship between students' behavioral intentions and perceptions of service dimension.

Hypothesis 4b: There is a significant relationship between students' behavioral intentions and perceptions of service (transportation) dimension.

Hypothesis 4c: There is a significant relationship between students' behavioral intentions and their perception of staff size.

Hypothesis 4d: There is a significant relationship between students' behavioral intentions and their perception of enthusiasm dimension.

Hypothesis 4e: There is a significant relationship between students' behavioral intentions and their perceptions of safety dimension.

Turkish Studies - Social, 15(2) 

satisfaction.

Hypothesis 5: There is a significant relationship between students' behavioral intentions and perceptions.

Hypothesis 6: There is a significant relationship between student satisfaction and service quality

Hypothesis 6a: There is a significant relationship between students' satisfaction and their perception of service (transportation) dimension.

Hypothesis 6b: There is a significant relationship between students' satisfaction and perception of service dimension. perceptions.

Hypothesis 6c: There is a significant relationship between students' satisfaction and staff size

Hypothesis 6d: There is a significant relationship between students' satisfaction and their perception of enthusiasm.

Hypothesis 6e: There is a significant relationship between students' satisfaction and their perception of security dimension.

\section{Methods}

The population of the research is the students studying at Çankırı Karatekin University and using them to intercity bus companies. The sample of the study was 424 students who accepted to participate in the study. In the research, questionnaire technique was used as data collection technique. The questionnaire consisted of two parts, in the first part questions were asked about the demographic characteristics of the students, in the second part, the service quality scale consisting of 5 dimensions (Service, service (transportation), personnel, responsiveness and security) and 28 statements to determine the quality of service, and 7 statements to determine the behavioral intentions of the students. five-point Likert-type scales were used to determine the general satisfaction of students. Duman, Ayduğan and Koçuk (2007), Y1lmaz (2012), Koçoğlu and Aksoy (2012), Özdipçiner and Ceylan (2016) and Aliçavuşoğlu and Gürbüz (2017) were used in the preparation of the questionnaire. The statistical analysis of the questionnaire, which was answered by 424 students, was carried out with IBM SPSS 22 statistical package program. Frequency distribution, descriptive statistics, T test, one-factor analysis of variance and correlation tests were used in the analysis of the data.

\section{Results}

Among the demographic variables examined, a statistically significant difference was found between the students' class and the general satisfaction of the students for bus companies. There was found between students' behavioral intentions and perceived service quality dimensions (Service, service (transportation), personnel, responsiveness and security) a positive, high, medium, medium, medium and medium relationship. There was a positive, weak, weak, weak, weak and weak relationship between students' general satisfaction and service quality dimensions (Service, service (transportation), personnel, responsiveness and security) and (positive) medium relationship between behavioral intentions and general satisfaction of students.

According to the results of the research, hypothesis 1 and its sub-hypotheses were rejected. Hypothesis 2 has been rejected. Hypothesis 3 has been partially accepted. Hypothesis 4, hypothesis 5 , hypothesis 6 and lower hypotheses of these hypotheses are accepted.

Keywords: Service Quality, Behavioral Intention, Satisfaction, Cankiri Karatekin University, Bus Passengers.

Öz: $\mathrm{Bu}$ araştırmada şehirlerarası otobüs işletmelerinde algılanan hizmet kalitesi, davranışsal niyet ile memnuniyetin öğrencilerin demografik özelliklerine göre anlamlı bir farklılık gösterip göstermediği ile şehirlerarası otobüs işletmelerinde algılanan hizmet kalitesi, davranışsal niyet ve memnuniyet arasındaki ilişki araştırılmıştır. Araştırmanın evreni Çankırı Karatekin Üniversitesinde eğitim gören ve şehirlerarası otobüs işletmelerine kullanan öğrencilerdir. Araştırmanın örneklemi araştırmaya katılmayı kabul eden 424 öğrencidir. Araştırmada veri toplama tekniği olarak anket tekniği kullanılmıştır. Anket formu iki bölümden 
oluşmuştur, ilk bölümde öğrencilerin demografik özellikleri ile ilgili sorular sorulmuştur, ikinci bölümde ise hizmet kalitesinin belirlenmesine yönelik 5 boyut (Hizmet, servis, personel, heveslilik ve güvenlik) ve 28 ifadeden oluşan hizmet kalite ölçeği ile öğrencilerin davranışsal niyetlerine belirlemeye yönelik 7 ifade ile öğrencilerin genel memnuniyetini belirlemeye yönelik bir ifadenin yer aldığı beşli likert tipinde ölçekler kullanılmıştır. Anket formunun hazırlanmasında Duman, Ayduğan ve Koçuk (2007), Yılmaz (2012), Koçoğlu ve Aksoy (2012), Özdipçiner ve Ceylan (2016) ile Aliçavuşoğlu ve Gürbüz (2017) ölçeklerinden yararlanılmıştır. Araştırmanın örneklemini oluşturan 424 öğrenci tarafından cevaplandırılan anketin istatistikî analizi IBM SPSS 22 istatistik paket programı ile gerçekleştirilmiştir. Verilerin analizinde frekans dağılımı, betimsel istatistikler, T testi, tek faktörlü varyans analizi ve korelasyon testleri kullanılmıştır. İncelenen demografik değişkenlerden öğrencilerin okudukları sınıf ile öğrencilerin otobüs işletmelerine yönelik genel memnuniyetleri arasında istatistiksel olarak anlamlı bir farklılık bulunmuştur. Öğrencilerin davranışsal niyetleri ile algılanan hizmet kalitesi boyutları arasında (Hizmet, servis, personel, heveslilik ve güvenlik) doğru yönlü (pozitif) yüksek, orta, orta, orta ve orta bir ilişki, öğrencilerin genel memnuniyetleri ile hizmet kalitesi boyutları arasında (Hizmet, servis, personel, heveslilik ve güvenlik) doğru yönlü (pozitif) zayıf, zayıf, zayıf, zayıf ve zayıf bir ilişki ve öğrencileri davranışsal niyetleri ile genel memnuniyetleri arasında doğru yönlü (pozitif) orta bir ilişki bulunmuştur.

Anahtar Kelimeler: Hizmet Kalitesi, Davranışsal Niyet, Memnuniyet, Çankırı Karatekin Üniversitesi, Otobüs Yolcuları.

\section{Giriş}

Hizmet kalitesi ile ilgili literatür incelendiğinde, hizmet kalitesi konusunda yapılan tanımların hizmet sektörüne ve sunulan hizmetin niteliğine göre farklılıklar gösterdiği, kaliteli bir hizmet için müşterilerin beklentileri doğrultusunda sunulan hizmetin bu müşteri beklentilerinin ötesine geçmesinin gerekliliği ya da en azından müşteri beklentilerinin karşılayacak düzeyde hizmet verilmesi gerekliliği üzerinde durulduğu görülmüştür (Demirel, 2014: 22). Hizmet kalitesi düzeyi hakkında doğru bilgilere ulaşabilen işletme hizmet kalitesinin geliştirilmesine ya da hizmet kalitesindeki aksamalara yönelik sonraki aşamalarda alınacak tedbirleri yönelik daha etkili adımlar atabilecektir (Eleren vd., 2007: 78). Müşterilerin hizmet kalitesine yönelik tatmin düzeylerinin göstergesi olan memnuniyet veya memnuniyetsizlik sebepleri, hizmet kalitesinin değerlendirilmesindeki önemli faktörlerin belirlenmesinde, hizmetle ilgili müşterilerin çalışanlardan beklediği performans belirlenmesinde ve hizmet kalitesini belirlenmesinde belirleyinci etkenler olarak görülmektedir (Turan, 2014: 20). Memnuniyet sürecinin bir sonucu olan davranışsal niyet boyutlarını müşteri sadakati, işletmeden ayrılma, daha fazla ödeme, tavsiye ve şikâyet nedenleri olarak özetlemek mümkündür (Güven ve Sarışık, 2014:29). Müşterilerin bir işletmeyi ve onun ürünlerini tekrar tercih etme niyetleri ve onun hakkındaki olumlu düşüncelerini potansiyel müşterilere iletmeleri, sunulan hizmetin kalitesi ve müşteri memnuniyeti gibi hususlardan etkilenerek şekillenir (Arlı, 2012:22). Bu araştırmada şehirlerarası otobüs işletmelerinde algılanan hizmet kalitesi, davranışsal niyet ile memnuniyetin öğrencilerin demografik özelliklerine göre anlamlı bir farklılık gösterip göstermediği ve şehirlerarası otobüs işletmelerinde algılanan hizmet kalitesi, davranışsal niyet ve memnuniyet arasındaki ilişki araştırılmıştır. Yapılan araştırmada hizmet kalitesi algısını hizmet, personel, servis, heveslilik ve güvenlik olmak üzere beş temel faktörün belirlediği saptanmıştır.

\section{Amaç}

$\mathrm{Bu}$ araştırmada şehirlerarası otobüs işletmelerinde algılanan hizmet kalitesi, davranışsal niyet ile memnuniyetin öğrencilerin demografik özelliklerine göre anlamlı bir farklılık gösterip göstermediği ve şehirlerarası otobüs işletmelerinde algılanan hizmet kalitesi, davranışsal niyet ve memnuniyet arasındaki ilişki araştırılmıştır. $\mathrm{Bu}$ amaç doğrultusunda aşağıdaki hipotezler geliştirilmiştir: 
Hipotez 1: Öğrencilerin hizmet kalitesi algısı demografik özelliklerine (cinsiyet, yaş ve kaçıncı sınıfta oldukları) göre anlamlı farklılık göstermektedir.

Hipotez 1a: Öğrencilerin hizmet boyutu algısı demografik özelliklerine (cinsiyet, yaş ve kaçıncı sınıfta oldukları) göre anlamlı farklılık göstermektedir

Hipotez 1b: Öğrencilerin servis boyutu algısı demografik özelliklerine (cinsiyet, yaş ve kaçıncı sınıfta oldukları) göre anlamlı farklılık göstermektedir.

Hipotez 1c: Öğrencilerin personel boyutu algısı demografik özelliklerine (cinsiyet, yaş ve kaçıncı sınıfta oldukları) göre anlamlı farklılık göstermektedir.

Hipotez 1d: Öğrencilerin heveslilik boyutu algısı demografik özelliklerine (cinsiyet, yaş ve kaçıncı sınıfta oldukları) göre anlamlı farklılık göstermektedir.

Hipotez 1e: Öğrencilerin güvenlik boyutu algısı demografik özelliklerine (cinsiyet, yaş ve kaçıncı sınıfta oldukları) göre anlamlı farklılık göstermektedir.

Hipotez 2: Öğrencilerin davranışsal niyetleri demografik özelliklerine (cinsiyet, yaş ve kaçıncı sınıfta oldukları) göre anlamlı farklılık göstermektedir.

Hipotez 3: Öğrencilerin memnuniyetleri demografik özelliklerine (cinsiyet, yaş ve kaçıncı sinıfta oldukları) göre anlamlı farklılık göstermektedir. ilişki vardır.

Hipotez 4: Öğrencilerin davranışsal niyetleri ile hizmet kalitesi algıları arasında anlamlı bir

Hipotez 4a: Öğrencilerin davranışsal niyetleri ile hizmet boyutu algıları arasında anlamlı bir ilişki vardır.

Hipotez 4b: Öğrencilerin davranışsal niyetleri ile servis boyutu algıları arasında anlamlı bir ilişki vardır.

Hipotez 4c: Öğrencilerin davranışsal niyetleri ile personel boyutu algıları arasında anlamlı bir ilişki vardır.

Hipotez 4d: Öğrencilerin davranışsal niyetleri ile heveslilik boyutu algıları arasında anlamlı bir ilişki vardır.

Hipotez 4e: Öğrencilerin davranışsal niyetleri ile güvenlik boyutu algıları arasında anlamlı bir ilişki vardır. vardir.

Hipotez 5: Öğrencilerin davranışsal niyetleri ile memnuniyetleri arasında anlamlı bir ilişki

Hipotez 6: Öğrencilerin memnuniyetleri ile hizmet kalitesi algıları arasında anlamlı bir ilişki vardır.

Hipotez 6a: Öğrencilerin memnuniyetleri ile hizmet boyutu algıları arasında anlamlı bir ilişki vardır.

Hipotez 6b: Öğrencilerin memnuniyetleri ile servis boyutu algıları arasında anlamlı bir ilişki vardır.

Hipotez 6c: Öğrencilerin memnuniyetleri ile personel boyutu algıları arasında anlamlı bir ilişki vardır.

Hipotez 6d: Öğrencilerin memnuniyetleri ile heveslilik boyutu algıları arasında anlamlı bir ilişki vardır.

www.turkishstudies.net/social 
Hipotez 6e: Öğrencilerin memnuniyetleri ile güvenlik boyutu algıları arasında anlamlı bir ilişki vardır.

\section{Kapsam}

Araştırmanın evreni, Çankırı Şehirlerarası Terminal İşletmesi (ÇAŞTİ)'nde faaliyet gösteren otobüs firmaları ile seyahat eden Çankırı Karatekin Üniversitesi öğrencileridir. Araştırma kapsamında Çankırı-Ankara, Çankırı-İstanbul güzergâhlarında karşılıklı yolcu taşımacılığ 1 yapan büyük otobüs firmaları araştırmaya dahil edilmiştir. ÇAŞTI' de faaliyet gösteren ve sadece haftanın belirli günlerinde sınırlı sayıda sefer düzenleyen diğer küçük firmalar ile ilçe belediye ve halk otobüsleri araştırmaya dahil edilmemiştir. Araştırmanın örneklemi araştırmaya katılmayı kabul eden 424 öğrencidir.

\section{Yöntem}

Araştırmanın verilerini elde etmek amacıyla anket tekniğine başvurulmuştur. Anket formunun hazırlanmasında Duman, Ayduğan ve Koçuk (2007), Yılmaz (2012), Koçoğlu ve Aksoy (2012), Özdipçiner ve Ceylan (2016) ile Aliçavuşoğlu ve Gürbüz (2017) araştırmalarında kullandıkları ölçeklerden yararlanılmıştır. Duman, Ayduğan ve Koçak (2007) tarafından Mersin'de yapılan araştırmada karayolu hizmet kalitesi algısını yazıhane-servis-terminal hizmetleri, seyahat süresinde alınan hizmetler ve mola yeri hizmetleri olmak üzere üç temel boyutun belirlediği saptanmıştır. Yılmaz (2012) tarafından Nevşehir'de yapılan araştırmada hizmet kalite algısını yazıhane, yazıhane görevlileri ve otobüs personeline ilișkin hususlar, otobüslere ve yolculuk esnasında sunulan hizmetlere ilişkin hususlar, güvenilirlik ile ilgili hususlar, şehir içi servis araçları ve görevlilerine ilişkin hususlar, mola ile ilgili hususlar ve yer ayırma, bilet satın alma ve bagaja ilişkin hususlar olmak üzere üç temel faktörün belirlediği saptanmıştır. Koçoğlu ve Aksoy (2012) tarafından Zonguldak'ta yapılan araştırmada hizmet kalite algısını nezaket, fiziki unsurlar, güvenilirlik, heveslilik ve yeterlilik olmak üzere beş temel faktörün belirlediği saptanmıştır. Özdipçiner ve Ceylan (2016) tarafindan şehirlerarası hizmet veren bir ulaşım işletmesinin yolcularının hizmet kalite algılarının ölçülmesinin amaçlandığı araştırmalarında hizmet kalitesi tek boyutta ölçülmüştür. Aliçavuşoğlu ve Gürbüz (2017) tarafindan Tokat'ta yapılan araştırmada hizmet kalite algısını personel tutum ve davranışları, fiziki unsurlar ve zamanında hizmet hususları olmak üzere üç temel boyutun belirlediği saptanmıştır. Yapılan araştırmada hizmet kalitesi algısını hizmet, personel, servis, heveslilik ve güvenlik olmak üzere beş temel faktörün belirlediği saptanmıştır. Ölçeklere ilişkin güvenirlik analizleri tablo 1 de verilmiştir. Anket formu iki bölümden oluşmuştur, ilk bölümde öğrencilerin demografik özellikleri ile ilgili sorular sorulmuştur, ikinci bölümde ise ulaştırma işletmelerine yönelik hizmet kalitesin belirlenmesine yönelik 28 ifade 5 boyuttan oluşan Hizmet Kalite Ölçeği ile öğrencilerin davranışsal niyetlerinin belirlenmesine yönelik davranışsal niyetlerin ölçümü konusunda yaygın olarak kullanılan ölçek Zeithaml vd.'nin (1996) kullandığı davranışsal niyetler ölçeği kullanılmıştır. Öğrencilerin ulaştırma işletmelerine yönelik genel memnuniyetini belirlemeye yönelik bir ifade kullanılmıştır. Ölçekte yer alan maddeler beşli Likert türünde 1=Kesinlikle Katılmıyorum, 2=Katılmıyorum, $3=\mathrm{Ne}$ Katılıyorum $\mathrm{Ne}$ Katılmıyorum, 4=Katılıyorum ve 5=Kesinlikle Katılıyorum şeklindedir. Araştırma sonucunda elde edilen veriler IBM SPSS 22 istatistik paket programı ile analiz edilmiştir. 


\begin{tabular}{|c|c|c|c|c|c|}
\hline Ölçek / Boyut & $\begin{array}{c}\text { Madde } \\
\text { Sayısı }\end{array}$ & $\begin{array}{c}\text { Cronbach Alpha } \\
\text { Katsayısı }\end{array}$ & Ortalama & $\begin{array}{c}\text { Standart } \\
\text { Sapma }\end{array}$ & KMO \\
\hline $\begin{array}{l}\text { Hizmet Kalitesi } \\
\text { Ölçeği }\end{array}$ & 28 & ,950 & 3,2395 & ,79157 & \multirow{9}{*}{,926 } \\
\hline Hizmet Boyutu & 10 & ,907 & 3,3118 & ,86896 & \\
\hline Servis Boyutu & 6 & 870 & 3,0920 & ,98194 & \\
\hline Personel Boyutu & 5 & ,871 & 3,4726 & ,97854 & \\
\hline \multicolumn{5}{|l|}{ Tablo 1'in devamı } & \\
\hline Heveslilik Boyutu & 4 & 829 & 3,1415 & ,98272 & \\
\hline Güvenlik Boyutu & 3 & ,734 & 3,0354 & ,97435 & \\
\hline Davranışsal Niyet & 7 & 881 & 3,0027 & ,98138 & \\
\hline Memnuniyet & 1 & - & 3,2395 & ,79157 & \\
\hline
\end{tabular}

Tablo 1'e göre ölçekte kullanılan 28 madde için Cronbach Alpha iç tutarlılık katsayısı 0,950 olarak hesaplanmıştır. Bu da ölçeğin yüksek derecede güvenilir bir ölçek $(0,80 \leq \alpha<1,00)$ olduğunu göstermektedir (Ural ve Kilıç, 2013, s. 280; Can, 2013, s. 343).

\section{Bulgular}

Bu bölümde araştırmadan elde edilen bulgulara yer verilmiştir.

Tablo 2. Öğrencilere İlişkin Demografik Özellikler

\begin{tabular}{cccc}
\hline Demografik Özellikler & Kategori & $\mathbf{n}$ & $\mathbf{\%}$ \\
\hline \multirow{2}{*}{ Cinsiyet } & Erkek & 235 & 55,4 \\
\cline { 2 - 4 } & Kadın & 189 & 44,6 \\
\hline \multirow{2}{*}{ Yaş } & 17-20 Yaş Arası & 150 & 35,4 \\
\cline { 2 - 4 } & 21-22 Yaş Arası & 176 & 41,5 \\
\cline { 2 - 4 } & 23 Yaş ve Üzeri & 98 & 23,1 \\
\hline \multirow{3}{*}{ Sinıf } & 1. Sınıf & 108 & 25,5 \\
& 2. Sinıf & 115 & 27,1 \\
\cline { 2 - 4 } & 3. Sinıf & 112 & 26,4 \\
\cline { 2 - 4 } & 4. Sınıf & 89 & 21,0 \\
\hline
\end{tabular}

Tablo 2'ye göre araştırmaya katılan öğrencilerin \%55,4 (235 kişi)'ü erkek, \%44,6 (189 kişi)'sı kadındır. Öğrencilerin yaş dağılımlarına bakıldığında 21-22 yaş grubunun \%41,5 (176 kişi) ile ilk sırada yer aldığı görülmektedir. Bu grubu büyüklüklerine göre sırası ile 17-20 yaş arası grup $\% 35,4$ (150 kişi) ile 23 yaş ve üzeri grubun \%23,1 (98 kişi) izlediği görülmektedir. Öğrencilerin okudukları sınıflara göre dağılımlarına bakıldığında \%27,1 (115 kişi) ile ikinci sınıf öğrencilerinin en büyük grubu oluşturdukları görülmektedir. Bu grubu büyüklüklerine göre sırası ile üçüncü sınıf öğrencileri \%26,4 (112 kişi), birinci sınıf öğrencileri \%25,5 (108 kişi) ve dördüncü sınıf öğrencilerinin \%21,0 (89 kişi) izlediği görülmektedir.

\section{Faktör Analizine İlişkin Bulgular}

Faktör analizi, birbiri ile ilişkili çok sayıdaki değişkeni az sayıda, anlamlı ve birbirinden bağımsız faktörler haline getirerek ölçmeyi az sayıda faktörle açıklamayı amaçlayan çok değişkenli istatistik tekniklerinden biridir (Kalaycı, 2014, s. 321; Çokluk, Şekercioğlu ve Büyüköztürk, 2012, s. 177). Hizmet Kalite Ölçeğinin faktör analizine uygunluğunu test etmek için öncelikle KMO (Kaiser-Meyer-Olkin) ve Bartlett testlerinin sonuçlarına bakılmıştır. Araştırmada örneklem yeterliliğini temsil eden KMO oranı 0,926 olarak belirlenmiştir. Bartlett Küresellik Testi (Bartlett's Test of Sphericity) sonucunda ise anlamlllık değeri $\mathrm{p}=0,000<0,05$ olarak belirlenmiştir. Test sonucunun anlamlı olması, veriler arasında ilişki olduğunu ifade etmektedir. Faktör sayısının 
belirlenmesinde Kaiser ölçütü temel alınmıştır. Bu ölçüte göre öz değeri (eigenvalue) 1'den büyük olan faktörler temel alınmakta, öz değeri 1 den küçük olan faktörler dikkate alınmaz böylece kaç faktörlü bir yapının ortaya çıktığı saptanmaktadır (Kalaycı, 2014, s. 322; ). Bu araştırmada veri derleme aracının faktör yapısını görmek için faktörlerin döndürülmesinde dik döndürme yöntemi olan Varimax yöntemi kullanılmıştır. Yapılan analiz sonucunda 28 maddeden oluşan ve özdeğeri 1'den büyük olan beş faktör olduğu görülmüştür. Bu faktörler, toplam varyansın \% 64,90'ını açıklamıştır. Belirlenen faktörlere ait adlandırmalar, özdeğer ve varyans yüzdelerine ilişkin değerler Tablo 3' te gösterilmiştir. Tablo 3'e göre hizmet kalite ölçeğine ilişkin boyutların hizmet boyutu, personel boyutu, servis boyutu, heveslilik boyutu ve güvenlik boyutu olarak adlandırıldığı görülmektedir.

Tablo 3. Faktör Yükleri, Ortak Varyans Değerleri, Ortalama ve Standart Sapma Değerleri

\begin{tabular}{|c|c|c|c|c|c|c|c|c|}
\hline \multirow[t]{2}{*}{ Faktör } & \multirow{2}{*}{$\begin{array}{c}\text { Madde } \\
1\end{array}$} & \multicolumn{4}{|c|}{ Faktör Yük Değeri } & & \multirow{2}{*}{$\begin{array}{c}\text { Ortalama } \\
3,4811\end{array}$} & \multirow{2}{*}{$\begin{array}{c}\text { Standart Sapma } \\
1,11708\end{array}$} \\
\hline & & ,765 & & & & & & \\
\hline \multirow{9}{*}{ 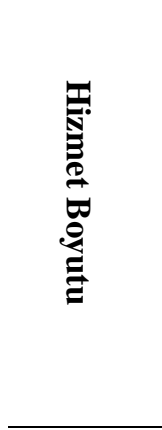 } & 2 & ,738 & & & & & 3,5590 & 1,15524 \\
\hline & 3 &, 660 & & & & & 3,5425 & 1,07104 \\
\hline & 4 & ,652 & & & & & 3,2241 & 1,12537 \\
\hline & 5 & ,646 & & & & & 3,4292 & 1,04946 \\
\hline & 6 & ,577 & & & & & 3,3278 & 1,19240 \\
\hline & 7 &, 548 & & & & & 3,2028 & 1,34442 \\
\hline & 8 & ,529 & & & & & 3,4717 & 1,21229 \\
\hline & 9 & ,458 & & & & & 3,2736 & 1,14469 \\
\hline & 10 & ,405 & & & & & 3,4811 & 1,11708 \\
\hline \multirow{6}{*}{ 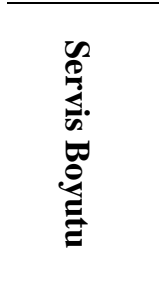 } & 1 & &, 811 & & & & 3,2146 & 1,21210 \\
\hline & 2 & & ,799 & & & & 3,2547 & 1,20920 \\
\hline & 3 & & ,741 & & & & 2,9599 & 1,29403 \\
\hline & 4 & & ,640 & & & & 3,0637 & 1,25221 \\
\hline & 5 & &, 552 & & & & 3,3915 & 1,18203 \\
\hline & 6 & &, 518 & & & & 2,6675 & 1,40424 \\
\hline \multirow{5}{*}{ 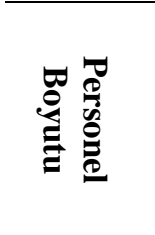 } & 1 & & & ,771 & & & 3,5236 & 1,25078 \\
\hline & 2 & & & ,768 & & & 3,8255 & 1,26143 \\
\hline & 3 & & &, 724 & & & 3,3774 & 1,16856 \\
\hline & 4 & & & ,690 & & & 3,2854 & 1,18149 \\
\hline & 5 & & &, 405 & & & 3,3514 & 1,15944 \\
\hline \multirow{4}{*}{ 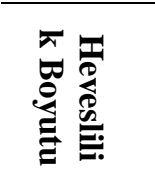 } & 1 & & & & $\mathbf{8 1 1}$ & & 3,2099 & 1,18533 \\
\hline & 2 & & & &, 650 & & 3,1274 & 1,22727 \\
\hline & 3 & & & &, 610 & & 3,0165 & 1,33234 \\
\hline & 4 & & & &, $\mathbf{5 8 9}$ & & 3,2123 & 1,07507 \\
\hline \multirow{4}{*}{ 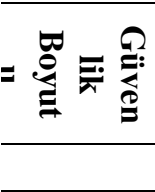 } & 1 & & & & & ,739 & 2,9528 & 1,29105 \\
\hline & 2 & & & & &, 583 & 3,1297 & 1,15456 \\
\hline & 3 & & & & &, 553 & 3,0236 & 1,34020 \\
\hline & Öz Değerler & 12,30 & 1,81 & 1,51 & 1,33 & 1,24 & & \\
\hline \multicolumn{2}{|c|}{ Açıklanan Varyans \% si } & 43,91 & 6,46 & 5,38 & 4,75 & 4,41 & & \\
\hline
\end{tabular}


Tablo 4. Hizmet Kalite Ölçeği Boyutlarının Maddeleri Dağılımı, Ortalaması ve Standart Sapması

\begin{tabular}{|c|c|c|c|c|c|c|c|c|c|c|c|c|c|}
\hline \multirow[t]{2}{*}{ Boyut } & \multirow[t]{2}{*}{ İfade } & \multicolumn{2}{|c|}{$\begin{array}{c}\text { Kesinlikle } \\
\text { Katılıyorum }\end{array}$} & \multicolumn{2}{|c|}{ Katılıyorum } & \multicolumn{2}{|c|}{$\begin{array}{c}\text { Ne } \\
\text { Katılıyorum } \\
\text { Ne } \\
\text { Katılmıyorum } \\
\end{array}$} & \multicolumn{2}{|c|}{ Katılmiyorum } & \multicolumn{2}{|c|}{$\begin{array}{c}\text { Kesinlikle } \\
\text { Katılmıyorum }\end{array}$} & \multirow[b]{2}{*}{ Ort. } & \multirow[b]{2}{*}{ S.S. } \\
\hline & & $\mathbf{n}$ & $\%$ & $\mathbf{n}$ & $\%$ & $\mathbf{n}$ & $\%$ & $\mathbf{n}$ & $\%$ & $\mathbf{n}$ & $\%$ & & \\
\hline \multirow{10}{*}{ 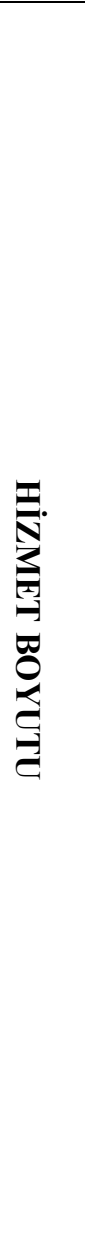 } & $\begin{array}{c}\text { Firma otobüsleri } \\
\text { görsel olarak çekici } \\
\text { ve otobüslerin içi } \\
\text { bakımlı ve temizdir. }\end{array}$ & 33 & 7,8 & 34 & 8,0 & 117 & 27,6 & 143 & 33,7 & 97 & 22,9 & 3,56 & 1,16 \\
\hline & $\begin{array}{l}\text { Firma otobüsleri } \\
\text { yenidir ve modern } \\
\text { ekipmana sahiptir. }\end{array}$ & 27 & 6,4 & 38 & 9,0 & 108 & 25,5 & 180 & 42,5 & 71 & 16,7 & 3,54 & 1,07 \\
\hline & $\begin{array}{c}\text { Firma otobüsleri } \\
\text { çekici bir yolculuk } \\
\text { ortamına(1s1, } \\
\text { havalandırma, anons } \\
\text { sistemi vb.) sahiptir. }\end{array}$ & 31 & 7,3 & 37 & 8,7 & 134 & 31,6 & 141 & 33,3 & 81 & 19,1 & 3,48 & 1,12 \\
\hline & $\begin{array}{l}\text { Bilet ayırtma ve } \\
\text { rezervasyon } \\
\text { işlemleri hatasız bir } \\
\text { şekilde } \\
\text { yapılmaktadır. }\end{array}$ & 44 & 10,4 & 52 & 12,3 & 62 & 14,6 & 192 & 45,3 & 74 & 17,5 & 3,47 & 1,21 \\
\hline & $\begin{array}{c}\text { Firma otobüsleri } \\
\text { hareket ve varış } \\
\text { saatlerine } \\
\text { uymaktadır. }\end{array}$ & 29 & 6,8 & 40 & 9,4 & 129 & 30,4 & 172 & 40,6 & 54 & 12,7 & 3,43 & 1,05 \\
\hline & $\begin{array}{l}\text { Firma otobüslerinde } \\
\text { sunulan yan } \\
\text { hizmetler (wifi, usb, } \\
\text { şarj, koltuk arkası } \\
\text { ekran) yeterlidir. }\end{array}$ & 44 & 10,4 & 53 & 12,5 & 116 & 27,4 & 142 & 33,5 & 69 & 16,3 & 3,33 & 1,19 \\
\hline & $\begin{array}{l}\text { Bagaj işlemleri } \\
\text { sorunsuz şekilde } \\
\text { yürütülmektedir. }\end{array}$ & 42 & 9,9 & 49 & 11,6 & 144 & 34,0 & 129 & 30,4 & 60 & 14,2 & 3,27 & 1,14 \\
\hline & $\begin{array}{l}\text { Firma yazıhanesi } \\
\text { temiz ve bakımlıdır. }\end{array}$ & 41 & 9,7 & 56 & 13,2 & 146 & 34,4 & 129 & 30,4 & 52 & 12,3 & 3,22 & 1,13 \\
\hline & $\begin{array}{c}\text { Yolculuk esnasında } \\
\text { yapılan ikramlar } \\
\text { çeşit ve kalite olarak } \\
\text { yeterlidir }\end{array}$ & 75 & 17,7 & 50 & 11,8 & 86 & 20,3 & 140 & 33,0 & 73 & 17,2 & 3,20 & 1,34 \\
\hline & $\begin{array}{c}\text { Bilet fiyatları diğer } \\
\text { firmalara göre daha } \\
\text { uygundur. }\end{array}$ & 118 & 27,8 & 93 & 21,9 & 89 & 21,0 & 86 & 20,3 & 38 & 9,0 & 2,61 & 1,32 \\
\hline \multirow{6}{*}{ 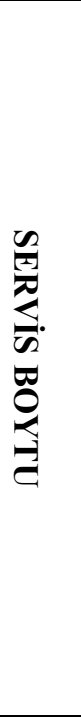 } & $\begin{array}{c}\text { Şehir içi servis } \\
\text { görevlisinin sizi } \\
\text { gitmek istediğiniz } \\
\text { yere yönlendirme } \\
\text { kabiliyeti yüksektir. }\end{array}$ & 46 & 10,8 & 33 & 7,8 & 128 & 30,2 & 143 & 33,7 & 74 & 17,5 & 3,39 & 1,18 \\
\hline & $\begin{array}{l}\text { Firmanın şehir içi } \\
\text { servis güzergah ve } \\
\text { durakları yeterlidir. }\end{array}$ & 45 & 10,6 & 65 & 15,3 & 120 & 28,3 & 125 & 29,5 & 69 & 16,3 & 3,25 & 1,21 \\
\hline & $\begin{array}{c}\text { Firmanın şehir içi } \\
\text { servis hizmetleri } \\
\text { zamanında hareket } \\
\text { etmektedir. }\end{array}$ & 49 & 11,6 & 52 & 12,3 & 158 & 37,3 & 89 & 21,0 & 76 & 17,9 & 3,21 & 1,21 \\
\hline & $\begin{array}{l}\text { Firmanın şehir içi } \\
\text { servis araçlarının } \\
\text { sayısı yeterlidir. }\end{array}$ & 64 & 15,1 & 64 & 15,1 & 140 & 33,0 & 93 & 21,9 & 63 & 14,9 & 3,06 & 1,25 \\
\hline & $\begin{array}{l}\text { Firmanın şehir içi } \\
\text { servis hizmetleri } \\
\text { sıklıkla hareket } \\
\text { etmektedir. }\end{array}$ & 71 & 16,7 & 87 & 20,5 & 117 & 27,6 & 86 & 20,3 & 63 & 14,9 & 2,96 & 1,29 \\
\hline & $\begin{array}{l}\text { Firmanın şehir içi } \\
\text { servis hizmetleri } \\
\text { konforludur. } \\
\end{array}$ & 136 & 32,1 & 54 & 12,7 & 98 & 23,1 & 87 & 20,5 & 49 & 11,6 & 2,67 & 1,40 \\
\hline
\end{tabular}




\begin{tabular}{|c|c|c|c|c|c|c|c|c|c|c|c|c|c|}
\hline & Tablo 4'ün devamı & & & & & & & & & & & & \\
\hline \multirow{5}{*}{ 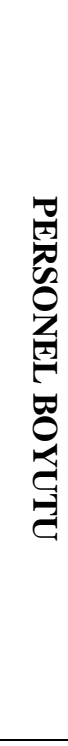 } & $\begin{array}{c}\text { Bilet ve rezervasyon } \\
\text { görevlileri yolculara } \\
\text { karşı güler yüzlü ve } \\
\text { nezaketlidir. }\end{array}$ & 42 & 9,9 & 24 & 5,7 & 56 & 13,2 & 146 & 36,8 & 156 & 36,8 & 3,93 & 1,26 \\
\hline & $\begin{array}{l}\text { Bilet ve rezervasyon } \\
\text { görevlileri } \\
\text { rezervasyon ve bilet } \\
\text { işlemlerini hızlı bir } \\
\text { şekilde } \\
\text { gerçekleştirmektedir. }\end{array}$ & 50 & 11,8 & 32 & 7,5 & 84 & 19,8 & 162 & 38,2 & 96 & 22,6 & 3,52 & 1,25 \\
\hline & $\begin{array}{c}\text { Bilet ve rezervasyon } \\
\text { görevlileri yolcuları } \\
\text { doğru şekilde } \\
\text { bilgilendirmektedir. }\end{array}$ & 43 & 10,1 & 33 & 7,8 & 146 & 34,4 & 125 & 29,5 & 77 & 18,2 & 3,38 & 1,17 \\
\hline & $\begin{array}{c}\text { Şoförler, muavinler, } \\
\text { host ve hostesler } \\
\text { yolculara karşı güler } \\
\text { yüzlü ve } \\
\text { nezaketlidir. }\end{array}$ & 39 & 9,2 & 53 & 12,5 & 118 & 27,8 & 148 & 34,9 & 66 & 15,6 & 3,35 & 1,16 \\
\hline & $\begin{array}{l}\text { Şoförler, muavinler, } \\
\text { host ve hostesler iyi } \\
\text { giyimli ve zarif } \\
\text { görünümlüdür. }\end{array}$ & 40 & 9,4 & 67 & 15,8 & 114 & 26,9 & 138 & 32,5 & 65 & 15,3 & 3,29 & 1,18 \\
\hline \multirow{4}{*}{ 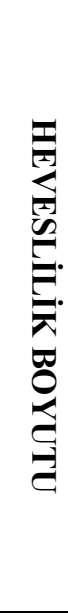 } & $\begin{array}{c}\text { Firma çalışanları } \\
\text { yolculara her zaman } \\
\text { yardım etmede } \\
\text { isteklidir. }\end{array}$ & 38 & 9,0 & 50 & 11,8 & 165 & 38,9 & 126 & 29,7 & 45 & 10,6 & 3,21 & 1,08 \\
\hline & $\begin{array}{c}\text { Bilet ve rezervasyon } \\
\text { görevlileri } \\
\text { yolcuların } \\
\text { sorunlarına karşı } \\
\text { ilgilidir. }\end{array}$ & 46 & 10,8 & 55 & 13,0 & 156 & 34,8 & 98 & 23,1 & 69 & 16,3 & 3,21 & 1,19 \\
\hline & $\begin{array}{c}\text { Firma çalışanları } \\
\text { yolcuların } \\
\text { şikâyetlerini dikkate } \\
\text { almaktadır. }\end{array}$ & 53 & 12,5 & 77 & 18,2 & 116 & 27,4 & 119 & 28,1 & 59 & 13,9 & 3,13 & 1,23 \\
\hline & $\begin{array}{l}\text { Şoförler, muavinler, } \\
\text { host ve hostesler } \\
\text { seyahat esnasında } \\
\text { yolcuların özel } \\
\text { ihtiyaçlarına ilgi } \\
\text { gösterir. } \\
\end{array}$ & 82 & 19,3 & 72 & 17,7 & 81 & 19,1 & 135 & 31,8 & 54 & 12,7 & 3,02 & 1,33 \\
\hline \multirow{3}{*}{ 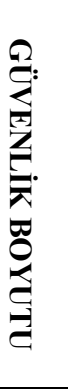 } & $\begin{array}{c}\text { Firma yolcularının } \\
\text { tamamına ferdi kaza } \\
\text { sigortası } \\
\text { yapmaktadır. }\end{array}$ & 53 & 12,5 & 45 & 10,6 & 174 & 41,0 & 98 & 23,1 & 54 & 12,7 & 3,13 & 1,15 \\
\hline & $\begin{array}{l}\text { Firma yolcuların } \\
\text { güvenli bir şekilde } \\
\text { yolculuk etmesini } \\
\text { sağlamaktadır. } \\
\end{array}$ & 74 & 17,5 & 84 & 19,8 & 93 & 21,9 & 104 & 24,5 & 69 & 16,3 & 3,02 & 1,34 \\
\hline & $\begin{array}{c}\text { Firma şoförleri hız } \\
\text { sinırlamalarına ve } \\
\text { trafik kurallarına } \\
\text { uyar. }\end{array}$ & 87 & 20,5 & 44 & 10,4 & 153 & 36,1 & 82 & 19,3 & 58 & 13,7 & 2,95 & 1,29 \\
\hline
\end{tabular}

Tablo 4'e göre hizmet boyutuna ilişin genel ortalaması en yüksek ifadenin "Firma otobüsleri görsel olarak çekici ve otobüslerin içi bakımlı ve temizdir" ifadesinin, genel ortalaması endüşük olan ifadenini ise "Bilet fiyatları diğer firmalara göre daha uygundur" ifadesi olduğu görülmektedir. Servis boyutuna ilişin genel ortalaması en yüksek ifadenin "Firmanın şehir içi servis görevlisinin sizi gitmek istediğiniz yere yönlendirme kabiliyeti yüksektir" ifadesinin, genel ortalaması endüşük olan ifadenini ise "Firmanın şehir içi servis hizmetleri konforludur" ifadesi olduğu görülmektedir. Personel boyutuna ilişin genel ortalaması en yüksek ifadenin "Bilet ve 
rezervasyon görevlileri yolculara karşı güler yüzlü ve nezaketlidir.” ifadesinin, genel ortalaması endüşük olan ifadenini ise "Şoförler, muavinler, host ve hostesler iyi giyimli ve zarif görünümlüdür." ifadesi olduğu görülmektedir. Heveslilik boyutuna ilişin genel ortalaması en yüksek ifadenin "Firma çalışanları yolculara her zaman yardım etmede isteklidir" ifadesinin, genel ortalaması endüşük olan ifadenini ise "Şoförler, muavinler, host ve hostesler seyahat esnasında yolcuların özel ihtiyaçlarına ilgi gösterir" ifadesi olduğu görülmektedir. Güvenlik boyutuna ilişin genel ortalaması en yüksek ifadenin "Firma yolcularının tamamına ferdi kaza sigortası yapmaktadır" ifadesinin, genel ortalaması endüşük olan ifadenini ise "Firma şoförleri hız sınırlamalarına ve trafik kurallarına uyar" ifadesi olduğu görülmektedir.

Tablo 5. Davranışsal Niyet Ölçeği Maddeleri Dağılımı, Ortalaması ve Standart Sapması

\begin{tabular}{|c|c|c|c|c|c|c|c|c|c|c|c|c|c|}
\hline \multirow[t]{2}{*}{ Boyut } & \multirow[t]{2}{*}{ İfade } & \multicolumn{6}{|c|}{$\begin{array}{c}\text { Ne } \\
\text { Katılıyorum } \\
\text { Ne } \\
\text { Katılmiyorum } \\
\end{array}$} & \multicolumn{2}{|c|}{ Katılmiyorum } & \multicolumn{2}{|c|}{$\begin{array}{c}\text { Kesinlikle } \\
\text { Katılmıyorum }\end{array}$} & \multirow[b]{2}{*}{ Ort. } & \multirow[b]{2}{*}{ S.S. } \\
\hline & & $\mathbf{n}$ & $\%$ & $\mathbf{n}$ & $\%$ & $\mathbf{n}$ & $\%$ & n & $\%$ & $\mathbf{n}$ & $\%$ & & \\
\hline \multirow{7}{*}{ 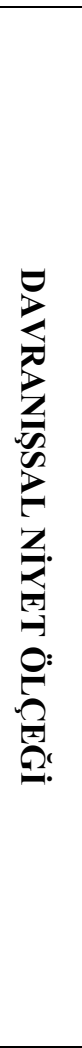 } & $\begin{array}{c}\text { Başka bir } \\
\text { seyahatimde bu } \\
\text { firmayı tekrar } \\
\text { tercih etmek } \\
\text { seçeneklerim } \\
\text { arasında olur. }\end{array}$ & 60 & 14,2 & 30 & 7,1 & 131 & 30,9 & 149 & 35,1 & 54 & 12,7 & 3,25 & 1,99 \\
\hline & $\begin{array}{c}\text { Tercih ettiğim } \\
\text { firmayı başkalarına } \\
\text { tavsiye ederim. }\end{array}$ & 72 & 17,0 & 40 & 9,4 & 113 & 26,7 & 129 & 30,4 & 70 & 16,5 & 3,20 & 1,30 \\
\hline & $\begin{array}{l}\text { Bu firma hakkında } \\
\text { fikrim } \\
\text { sorulduğunda } \\
\text { olumlu yorumlarda } \\
\text { bulunacağım. }\end{array}$ & 57 & 13,4 & 65 & 15,3 & 130 & 30,7 & 103 & 24,3 & 69 & 16,3 & 3,15 & 1,25 \\
\hline & $\begin{array}{c}\text { Bu firmada } \\
\text { edindiğim seyahat } \\
\text { deneyimimi başka } \\
\text { kişilerle } \\
\text { paylaşmaktan } \\
\text { mutluluk } \\
\text { duyacağım. }\end{array}$ & 77 & 18,2 & 46 & 10,8 & 130 & 30,7 & 104 & 24,5 & 67 & 15,8 & 3,09 & 1,31 \\
\hline & $\begin{array}{l}\text { Kendimi firmanın } \\
\text { sadık bir müşterisi } \\
\text { olarak görüyorum. }\end{array}$ & 74 & 17,5 & 61 & 14,4 & 151 & 55,6 & 80 & 18,9 & 58 & 13,7 & 2,97 & 1,26 \\
\hline & $\begin{array}{c}\text { Diğer firmaların } \\
\text { yaptığı fiyat } \\
\text { indirimleri firma } \\
\text { tercihimi etkilemez. }\end{array}$ & 100 & 23,6 & 74 & 17,5 & 94 & 22,2 & 103 & 24,3 & 53 & 12,5 & 2,85 & 1,36 \\
\hline & $\begin{array}{c}\text { Firmanın ulaştırma } \\
\text { fiyatları artsa bile } \\
\text { müşterisi olmaya } \\
\text { devam ederim. }\end{array}$ & 137 & 32,3 & 60 & 14,2 & 107 & 25,2 & 84 & 19,8 & 34 & 8,0 & 2,57 & 1,33 \\
\hline
\end{tabular}

Tablo 5'e göre davranışsal niyet ölçeğine ilişin genel ortalaması en yüksek ifadenin "Başka bir seyahatimde bu firmayı tekrar tercih etmek seçeneklerim arasında olur" ifadesinin, genel ortalaması endüşük olan ifadenini ise "Firmanın ulaştırma fiyatları artsa bile müşterisi olmaya devam ederim" ifadesi olduğu görülmektedir.

\section{Hipotezlerin Test Edilmesi}

Hipotez 1: Öğrencilerin hizmet kalitesi algısı demografik özelliklerine (cinsiyet, yaş ve kaçıncı sınıfta oldukları) göre anlamlı farklılık göstermektedir. 
Tablo 6’ya göre öğrencilerin cinsiyetleri, yaşları ve okudukları sınıflara göre hizmet kalite algılamalarında anlamlı bir farklılık görülmemiştir.

Tablo 6. Öğrencilerin Demografik Özellikleri İle Hizmet Kalitesi Ölçeği Arasındaki Farklılığa İlişkin T-Testi ve Anova Testi Sonuçları

\begin{tabular}{|c|c|c|c|c|c|c|c|c|}
\hline $\begin{array}{c}\text { Ölçek / } \\
\text { Boyut }\end{array}$ & Değişken & Grup & $\mathbf{n}$ & Ortalama & $\begin{array}{c}\text { Standart } \\
\text { Sapma }\end{array}$ & $F / t$ & $\mathbf{p}$ & $\begin{array}{c}\text { Tukey } \\
\text { HSD }\end{array}$ \\
\hline \multirow{9}{*}{ 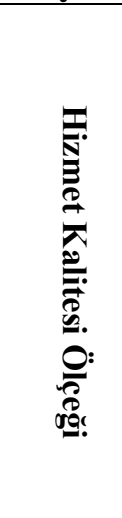 } & \multirow{2}{*}{ Cinsiyet } & Erkek & 235 & 3,2609 & ,79598 & \multirow{2}{*}{,623 } & \multirow{2}{*}{, 534} & \multirow{2}{*}{ - } \\
\hline & & Kadın & 189 & 3,2128 & ,78734 & & & \\
\hline & \multirow{3}{*}{ Yaş } & $17-20$ Yaş Arası $1^{\mathrm{a}}$ & 150 & 3,1902 & ,84771 & \multirow{3}{*}{, 523} & \multirow{3}{*}{, 593} & \multirow{3}{*}{-} \\
\hline & & $21-22$ Yaş Arası & 176 & 3,2802 & ,76170 & & & \\
\hline & & 23 Yaş ve Üzeric $^{\mathrm{c}}$ & 98 & 3,2416 & ,75834 & & & \\
\hline & \multirow{4}{*}{$\begin{array}{c}\text { Okunulan } \\
\text { Sinıf }\end{array}$} & 1. Sinif ${ }^{\mathrm{a}}$ & 108 & 3,2841 & ,90107 & \multirow{4}{*}{, 211} & \multirow{4}{*}{,899 } & \multirow{4}{*}{ - } \\
\hline & & 2. Sinif ${ }^{b}$ & 115 & 3,2472 & ,65243 & & & \\
\hline & & 3. $\operatorname{Sin} 1 \mathrm{f}^{\mathrm{c}}$ & 112 & 3,2187 & ,90949 & & & \\
\hline & & 4. Sinit $\mathrm{f}^{\mathrm{d}}$ & 89 & 3,2014 & ,65215 & & & \\
\hline
\end{tabular}

Hipotez 1a: Öğrencilerin hizmet boyutu algısı demografik özelliklerine (cinsiyet, yaş ve kaçıncı sınıfta oldukları) göre anlamlı farklılık göstermektedir.

Tablo 7: Öğrencilerin Demografik Özellikleri İle Hizmet Boyutu Arasındaki Farklılığa İlişkin T-Testi ve Anova Testi Sonuçları

\begin{tabular}{|c|c|c|c|c|c|c|c|c|}
\hline $\begin{array}{c}\text { Ölçek / } \\
\text { Boyut }\end{array}$ & Değişken & Grup & $\mathbf{n}$ & Ortalama & $\begin{array}{c}\text { Standart } \\
\text { Sapma }\end{array}$ & $F / t$ & $\mathbf{p}$ & $\begin{array}{c}\text { Tukey } \\
\text { HSD }\end{array}$ \\
\hline \multirow{9}{*}{ 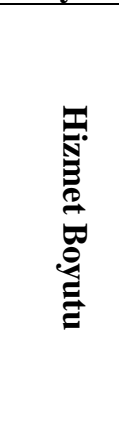 } & \multirow{2}{*}{ Cinsiyet } & Erkek & 235 & 3,3319 & ,84901 & \multirow{2}{*}{, 528} & \multirow{2}{*}{, 598} & \multirow[b]{2}{*}{ - } \\
\hline & & Kadın & 189 & 3,2868 & 89477 & & & \\
\hline & \multirow{3}{*}{ Yaş } & $17-20$ Yaş Arasia & 150 & 3,2820 & ,93522 & \multirow{3}{*}{, 300} & \multirow{3}{*}{,741 } & \multirow{3}{*}{ - } \\
\hline & & $21-22$ Yaş Arası & 176 & 3,3506 & 82953 & & & \\
\hline & & 23 Yaş ve Üzeric & 98 & 3,2878 & ,83854 & & & \\
\hline & \multirow{4}{*}{$\begin{array}{c}\text { Okunulan } \\
\text { Sinıf }\end{array}$} & 1. Sinif $f^{a}$ & 108 & 3,3843 & ,94386 & \multirow{4}{*}{,613 } & \multirow{4}{*}{,607 } & \multirow{4}{*}{ - } \\
\hline & & 2. $\operatorname{Sinif}^{\mathrm{b}}$ & 115 & 3,3461 & ,76826 & & & \\
\hline & & 3. Sinif $f^{c}$ & 112 & 3,2545 & ,97702 & & & \\
\hline & & 4. Sinif $f^{d}$ & 89 & 3,2517 & ,74956 & & & \\
\hline
\end{tabular}

Tablo 7'ye göre öğrencilerin cinsiyetleri, yaşları ve okudukları sınıflara göre hizmet boyutu algılamalarında anlamlı bir farklılık görülmemiştir.

Hipotez 1b: Öğrencilerin servis boyutu algısı demografik özelliklerine (cinsiyet, yaş ve kaçıncı sınıfta oldukları) göre anlamlı farklılık göstermektedir. 
Tablo 8: Öğrencilerin Demografik Özellikleri İle Servis Boyutu Arasındaki Farklılığa İlişkin TTesti ve Anova Testi Sonuçları

\begin{tabular}{|c|c|c|c|c|c|c|c|c|}
\hline $\begin{array}{c}\text { Ölçek / } \\
\text { Boyut }\end{array}$ & Değişken & Grup & $\mathbf{n}$ & Ortalama & $\begin{array}{c}\text { Standart } \\
\text { Sapma }\end{array}$ & $\mathbf{F} / \mathbf{t}$ & $\mathbf{p}$ & $\begin{array}{c}\text { Tukey } \\
\text { HSD }\end{array}$ \\
\hline \multirow{9}{*}{ 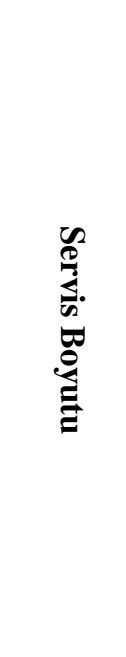 } & \multirow{2}{*}{ Cinsiyet } & Erkek & 235 & 3,0858 & ,97820 & \multirow{2}{*}{,- 144} & \multirow{2}{*}{,886 } & \multirow{2}{*}{ - } \\
\hline & & Kadın & 189 & 3,0996 & 98911 & & & \\
\hline & \multirow{3}{*}{ Yaş } & $17-20$ Yaş Arası ${ }^{\mathrm{a}}$ & 150 & 3,0678 & 98594 & \multirow{3}{*}{, 200} & \multirow{3}{*}{,819 } & \multirow{3}{*}{ - } \\
\hline & & $21-22$ Yaş Arası ${ }^{\mathrm{b}}$ & 176 & 3,1278 & ,98894 & & & \\
\hline & & 23 Yaş ve Üzeri ${ }^{\mathrm{c}}$ & 98 & 3,0646 & ,97113 & & & \\
\hline & \multirow{4}{*}{$\begin{array}{c}\text { Okunulan } \\
\text { Sinıf }\end{array}$} & 1. Sinif ${ }^{a}$ & 108 & 3,1636 & 1,02132 & \multirow{4}{*}{,314 } & \multirow{4}{*}{,816 } & \multirow{4}{*}{ - } \\
\hline & & 2. $\operatorname{Sin} 1 \mathrm{f}^{\mathrm{b}}$ & 115 & 3,0884 & ,86696 & & & \\
\hline & & 3. Sinif $f^{c}$ & 112 & 3,0744 & 1,09367 & & & \\
\hline & & 4. Sinit ${ }^{d}$ & 89 & 3,0318 & ,93470 & & & \\
\hline
\end{tabular}

Tablo 8'e göre öğrencilerin cinsiyetleri, yaşları ve okudukları sınıflara göre servis boyutu algılamalarında anlamlı bir farklılık görülmemiştir.

Hipotez 1c: Öğrencilerin personel boyutu algısı demografik özelliklerine (cinsiyet, yaş ve kaçıncı sınıfta oldukları) göre anlamlı farklılık göstermektedir.

Tablo 9: Öğrencilerin Demografik Özellikleri İle Personel Boyutu Arasındaki Farklılığa İlişkin T-Testi ve Anova Testi Sonuçları

\begin{tabular}{|c|c|c|c|c|c|c|c|c|}
\hline $\begin{array}{c}\text { Ölçek / } \\
\text { Boyut }\end{array}$ & Değişken & Grup & $\mathbf{n}$ & Ortalama & $\begin{array}{c}\text { Standart } \\
\text { Sapma }\end{array}$ & $\mathbf{F} / \mathbf{t}$ & $\mathbf{p}$ & $\begin{array}{c}\text { Tukey } \\
\text { HSD }\end{array}$ \\
\hline \multirow{9}{*}{ 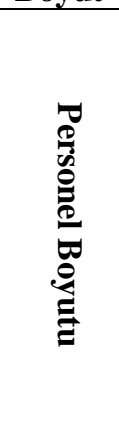 } & \multirow{2}{*}{ Cinsiyet } & Erkek & 235 & 3,3277 & ,90112 & \multirow{2}{*}{,- 135} & \multirow{2}{*}{, 893} & \multirow{2}{*}{ - } \\
\hline & & Kadın & 189 & 3,3397 & .92389 & & & \\
\hline & \multirow{3}{*}{ Yaş } & $17-20$ Yaş Arası ${ }^{\mathrm{a}}$ & 150 & 3,3853 & 1,01402 & \multirow{3}{*}{,932 } & \multirow{3}{*}{,395 } & \multirow{3}{*}{ - } \\
\hline & & $21-22$ Yaş Arası ${ }^{b}$ & 176 & 3,5261 & ,93038 & & & \\
\hline & & 23 Yaş ve Üzeri $^{\mathrm{c}}$ & 98 & 3,5102 & 1,00806 & & & \\
\hline & \multirow{4}{*}{$\begin{array}{c}\text { Okunulan } \\
\text { Sinıf }\end{array}$} & 1. Sinif ${ }^{a}$ & 108 & 3,4574 & 1,07410 & \multirow{4}{*}{053} & \multirow{4}{*}{,984 } & \multirow{4}{*}{-} \\
\hline & & 2. $\operatorname{Sin}_{1} \mathrm{f}^{\mathrm{b}}$ & 115 & 3,4678 & ,77996 & & & \\
\hline & & 3. $\operatorname{Sin}^{\mathrm{f}} \mathrm{c}$ & 112 & 3,5036 & 1,13550 & & & \\
\hline & & 4. Sinif ${ }^{\mathrm{d}}$ & 89 & 3,4584 & ,88534 & & & \\
\hline
\end{tabular}

Tablo 9'a göre öğrencilerin cinsiyetleri, yaşları ve okudukları sınıflara göre personel boyutu algılamalarında anlamlı bir farklılık görülmemiştir.

Hipotez 1d: Öğrencilerin heveslilik boyutu algısı demografik özelliklerine (cinsiyet, yaş ve kaçıncı sınıfta oldukları) göre anlamlı farklılık göstermektedir. 
Tablo 10. Öğrencilerin Demografik Özellikleri İle Heveslilik Boyutu Arasındaki Farklılığa İlişkin T-Testi ve Anova Testi Sonuçları

\begin{tabular}{|c|c|c|c|c|c|c|c|c|}
\hline $\begin{array}{c}\text { Ölçek / } \\
\text { Boyut }\end{array}$ & Değişken & Grup & $\mathbf{n}$ & Ortalama & $\begin{array}{c}\text { Standart } \\
\text { Sapma }\end{array}$ & $\mathbf{F} / \mathbf{t}$ & $\mathbf{p}$ & $\begin{array}{c}\text { Tukey } \\
\text { HSD }\end{array}$ \\
\hline \multirow{9}{*}{ 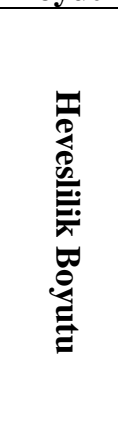 } & \multirow{2}{*}{ Cinsiyet } & Erkek & 235 & 3,1883 & ,98271 & \multirow{2}{*}{1,093} & \multirow{2}{*}{, 275} & \multirow{2}{*}{ - } \\
\hline & & Kadın & 189 & 3,0833 & ,98222 & & & \\
\hline & \multirow{3}{*}{ Yaş } & $17-20$ Yaş Arasia & 150 & 3,0933 & 1,00567 & \multirow{3}{*}{, 304} & \multirow{3}{*}{,738 } & \multirow{3}{*}{-} \\
\hline & & $21-22$ Yaş Arası ${ }^{b}$ & 176 & 3,1577 & ,97523 & & & \\
\hline & & 23 Yaş ve Üzeric & 98 & 3,1862 & ,96745 & & & \\
\hline & \multirow{4}{*}{$\begin{array}{c}\text { Okunulan } \\
\text { Sinıf }\end{array}$} & 1. Sinif $f^{a}$ & 108 & 3,1412 & 1,02667 & \multirow{4}{*}{,235 } & \multirow{4}{*}{, 872} & \multirow{4}{*}{-} \\
\hline & & 2. $\operatorname{Sin}_{1}{ }^{b}$ & 115 & 3,2022 & 88351 & & & \\
\hline & & 3. Sinif & 112 & 3,1161 & 1,08009 & & & \\
\hline & & 4. Sinit ${ }^{\mathrm{d}}$ & 89 & 3,0955 & ,93276 & & & \\
\hline
\end{tabular}

Tablo 10'a göre öğrencilerin cinsiyetleri, yaşları ve okudukları sınıflara göre heveslilik boyutu algılamalarında anlamlı bir farklılık görülmemiştir

Hipotez 1e: Öğrencilerin güvenlik boyutu algısı demografik özelliklerine (cinsiyet, yaş ve kaçıncı sınıfta oldukları) göre anlamlı farklılık göstermektedir.

Tablo 11. Öğrencilerin Demografik Özellikleri İle Güvenlikk Boyutu Arasındaki Farklılığa İlişkin

T-Testi ve Anova Testi Sonuçları

\begin{tabular}{|c|c|c|c|c|c|c|c|c|}
\hline $\begin{array}{l}\text { Ölçek / } \\
\text { Boyut }\end{array}$ & Değişken & Grup & $\mathbf{n}$ & Ortalama & $\begin{array}{c}\text { Standart } \\
\text { Sapma }\end{array}$ & $F / t$ & $\mathbf{p}$ & $\begin{array}{c}\text { Tukey } \\
\text { HSD }\end{array}$ \\
\hline \multirow{9}{*}{ 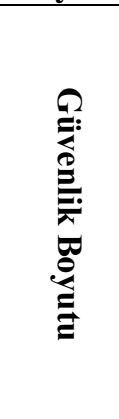 } & \multirow{2}{*}{ Cinsiyet } & Erkek & 235 & 3,0468 & ,93735 & \multirow{2}{*}{267} & \multirow{2}{*}{,790 } & \multirow{2}{*}{ - } \\
\hline & & Kadın & 189 & 3,0212 & 1,02083 & & & \\
\hline & \multirow{3}{*}{ Yaş } & $17-20$ Yaş Aras $^{\mathrm{a}}$ & 150 & 2,9333 & 1,01517 & \multirow{3}{*}{1,318} & \multirow{3}{*}{,269 } & \multirow{3}{*}{ - } \\
\hline & & $21-22$ Yaş Arası & 176 & 3,1042 & ,91333 & & & \\
\hline & & 23 Yaş ve Üzeri $^{\mathrm{c}}$ & 98 & 3,0680 & 1,01304 & & & \\
\hline & \multirow{4}{*}{$\begin{array}{c}\text { Okunulan } \\
\text { Sinıf }\end{array}$} & 1. Sinif $f^{a}$ & 108 & 3,0926 & 1,04104 & \multirow{4}{*}{,682 } & \multirow{4}{*}{,564 } & \multirow{4}{*}{ - } \\
\hline & & 2. Sinif ${ }^{b}$ & 115 & 2,9275 & ,84441 & & & \\
\hline & & 3. Sinif ${ }^{c}$ & 112 & 3,0506 & 1,06280 & & & \\
\hline & & 4. $\operatorname{Sin}^{\mathrm{f}^{\mathrm{d}}}$ & 89 & 3,0861 & ,93545 & & & \\
\hline
\end{tabular}

Tablo11'e göre öğrencilerin cinsiyetleri, yaşları ve okudukları sınıflara göre güvenlik boyutu algılamalarında anlamlı bir farklılık görülmemiştir.

Hipotez 2: Öğrencilerin davranışsal niyetleri demografik özelliklerine (cinsiyet, yaş ve kaçıncı sınıfta oldukları) göre anlamlı farklılık göstermektedir.

Tablo 12. Öğrencilerin Demografik Özellikleri İle Davranışsal Niyetleri Arasındaki Farklılığa İlişkin T-Testi ve Anova Testi Sonuçları

\begin{tabular}{|c|c|c|c|c|c|c|c|c|}
\hline $\begin{array}{l}\text { Ölçek / } \\
\text { Boyut }\end{array}$ & Değişken & Grup & $\mathbf{n}$ & Ortalama & $\begin{array}{c}\text { Standart } \\
\text { Sapma }\end{array}$ & $F / t$ & $\mathbf{p}$ & $\begin{array}{c}\text { Tukey } \\
\text { HSD }\end{array}$ \\
\hline \multirow{9}{*}{ 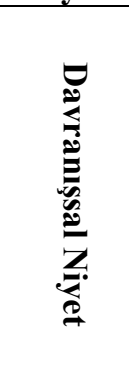 } & \multirow{2}{*}{ Cinsiyet } & Erkek & 233 & 2,9902 & ,96822 & \multirow[b]{2}{*}{,- 290} & \multirow{2}{*}{,772 } & \multirow[b]{2}{*}{ - } \\
\hline & & Kadın & 189 & 3,0181 & 99973 & & & \\
\hline & \multirow{3}{*}{ Yaş } & $17-20$ Yaș Arası $^{a}$ & 150 & 2,9648 & 1,04310 & \multirow{3}{*}{,201 } & \multirow{3}{*}{818} & \multirow{3}{*}{ - } \\
\hline & & $21-22$ Yaş Arasi ${ }^{b}$ & 174 & 3,0131 & ,92713 & & & \\
\hline & & 23 Yas ve Üzeric & 98 & 3,0423 & 98574 & & & \\
\hline & \multirow{4}{*}{$\begin{array}{c}\text { Okunulan } \\
\text { Sinıf }\end{array}$} & 1. Sinif ${ }^{\mathrm{a}}$ & 108 & 3,0265 & 1,07742 & \multirow{4}{*}{, 124} & \multirow{4}{*}{,946 } & \multirow{4}{*}{ - } \\
\hline & & 2. Sinit ${ }^{b}$ & 115 & 2,9727 & .88850 & & & \\
\hline & & 3. $\operatorname{Sin} 1 \mathrm{f}^{\mathrm{c}}$ & 110 & 2,9792 & 1,06919 & & & \\
\hline & & 4. $\operatorname{Sin} 1 f^{d}$ & 89 & 3,0417 & ,86795 & & & \\
\hline
\end{tabular}


Tablo 12’ye göre öğrencilerin cinsiyetleri, yaşları ve okudukları sınıflara göre davranışsal niyetlerinde anlamlı bir farklılık görülmemiştir.

Hipotez 3: Öğrencilerin memnuniyetleri demografik özelliklerine (cinsiyet, yaş ve kaçıncı sinıfta oldukları) göre anlamlı farklılık göstermektedir.

Tablo 13: Öğrencilerin Demografik Özellikleri İle Memnuniyetleri Arasındaki Farkl11ığa İlișkin T-Testi ve Anova Testi Sonuçları

\begin{tabular}{|c|c|c|c|c|c|c|c|c|}
\hline $\begin{array}{c}\text { Ölçek / } \\
\text { Boyut }\end{array}$ & Değişken & Grup & $\mathbf{n}$ & Ortalama & $\begin{array}{c}\text { Standart } \\
\text { Sapma }\end{array}$ & $F / t$ & $\mathbf{p}$ & $\begin{array}{c}\text { Tukey } \\
\text { HSD }\end{array}$ \\
\hline \multirow{9}{*}{ 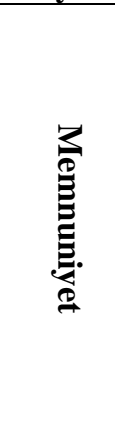 } & \multirow{2}{*}{ Cinsiyet } & Erkek & 235 & 3,3702 & ,99741 & \multirow{2}{*}{, 569} & \multirow{2}{*}{, 570} & \multirow{2}{*}{ - } \\
\hline & & Kadın & 189 & 3,3175 & ,90786 & & & \\
\hline & \multirow{3}{*}{ Yaş } & $17-20$ Yaş Arası $^{a}$ & 150 & 3,1867 & 1,00593 & \multirow{3}{*}{3,380} & \multirow{3}{*}{,035 } & \multirow{3}{*}{$\begin{array}{l}\text { b ile a } \\
\text { c ile a }\end{array}$} \\
\hline & & $21-22$ Yaş Arası & 176 & 3,4148 & ,95834 & & & \\
\hline & & 23 Yaş ve Üzeric ${ }^{\mathrm{c}}$ & 98 & 3,4694 & ,85197 & & & \\
\hline & \multirow{4}{*}{$\begin{array}{c}\text { Okunulan } \\
\text { Sinıf }\end{array}$} & 1. Sinif ${ }^{a}$ & 108 & 3,1481 & 1,08356 & \multirow{4}{*}{2,702} & \multirow{4}{*}{,045 } & \multirow{4}{*}{ d ile a } \\
\hline & & 2. $\operatorname{Sin}_{1} \mathrm{f}^{\mathrm{b}}$ & 115 & 3,3826 & ,86433 & & & \\
\hline & & 3. Sinif $\mathrm{f}^{\mathrm{c}}$ & 112 & 3,3571 & 1,04715 & & & \\
\hline & & 4. Sinif $\mathrm{f}^{\mathrm{d}}$ & 89 & 3,5281 & ,73993 & & & \\
\hline
\end{tabular}

Tablo 13'e göre öğrencilerin ulaştırma işletmelerine yönelik genel memnuniyetleri cinsiyetlerine göre anlamlı bir farklılık göstermemiştir. Öğrencilerin yaşları ve okudukları sınıflara göre genel memnuniyetleri anlamlı bir farklılık göstermiştir. Anlamlı farklılığın düşük yaş grubu ile diğer yaş grupları arasında olduğu arasında olduğu görülmektedir. 23 yaş ve üzeri grubun genel memnuniyet düzeylerinin en yüksek olduğu görülmektedir. Okunulan sınıfa göre ise anlamlı farklılığın dördüncü sınıf ile birinci sınıf öğrencileri arasında olduğu görülmektedir. Dördüncü sınıf öğrencilerinin genel memnuniyet düzeylerinin diğer sınıflara göre daha yüksek olduğu görülmektedir.

Hipotez 4: Öğrencilerin davranışsal niyetleri ile hizmet kalitesi algıları arasında anlamlı bir ilişki vardır.

Hipotez 4a: Öğrencilerin davranışsal niyetleri ile hizmet boyutu algıları arasında anlamlı bir ilişki vardır.

Hipotez 4b: Öğrencilerin davranışsal niyetleri ile servis boyutu algıları arasında anlamlı bir ilişki vardır.

Hipotez 4c: Öğrencilerin davranışsal niyetleri ile personel boyutu algıları arasında anlamlı bir ilişki vardır.

Hipotez 4d: Öğrencilerin davranışsal niyetleri ile heveslilik boyutu algıları arasında anlamlı bir ilişki vardır.

Hipotez 4e: Öğrencilerin davranışsal niyetleri ile güvenlik boyutu algıları arasında anlamlı bir ilişki vardır.

Tablo 14. Davranışsal Niyet Hizmet Kalitesi Algısı İlişkisi

\begin{tabular}{|c|c|c|c|c|c|c|c|}
\hline \multicolumn{2}{|c|}{ Pearson Korelasyon Matrisi } & $\begin{array}{l}\text { Hizmet } \\
\text { Kalitesi }\end{array}$ & $\begin{array}{l}\text { Hizmet } \\
\text { Boyutu }\end{array}$ & $\begin{array}{c}\text { Servis } \\
\text { Boyutu }\end{array}$ & $\begin{array}{c}\begin{array}{c}\text { Personel } \\
\text { Boyutu }\end{array} \\
\text { Bundu }\end{array}$ & $\begin{array}{c}\text { Heveslilik } \\
\text { Boyutu }\end{array}$ & $\begin{array}{c}\text { Güvenlik } \\
\text { Boyutu }\end{array}$ \\
\hline \multirow{3}{*}{$\begin{array}{c}\text { Davranışsal } \\
\text { Niyet }\end{array}$} & Pearson & $765^{* * *}$ & $688^{* * *}$ & $\mathbf{5 7 0}^{* *}$ & $664^{* *}$ & $642^{* * *}$ & $595^{* *}$ \\
\hline & Correlation & ,000 & ,000 & ,000 & ,000 & ,000 & ,000 \\
\hline & $\begin{array}{c}\text { Sig. (2-tailed) } \\
N\end{array}$ & 424 & 424 & 424 & 424 & 424 & 424 \\
\hline
\end{tabular}


Tablo 14'e göre öğrencilerin davranışsal niyetleri ile hizmet kalitesi algılamaları, hizmet boyutu, servis boyutu, personel boyutu, heveslilik boyutu ve güvenlik boyutu arasında doğru yönlü (pozitif) anlamlı yüksek, orta, orta, orta, orta ve orta bir ilişki bulunmuştur. vardır.

Hipotez 5: Öğrencilerin davranışsal niyetleri ile memnuniyetleri arasında anlamlı bir ilişki

Tablo 15. Memnuniyet Davranıșsal Niyet İlişkisi

\begin{tabular}{|c|c|c|}
\hline \multicolumn{2}{|c|}{ Pearson Korelasyon Matrisi } & Davranışsal Niyet \\
\hline \multirow{3}{*}{ Memnuniyet } & Pearson Correlation & $633^{* * *}$ \\
\hline & Sig. (2-tailed) &, 000 \\
\hline & $\mathrm{N}$ & 424 \\
\hline
\end{tabular}

Tablo 15'e göre öğrencilerin davranışsal niyetleri ile genel memnuniyetleri arasında doğru yönlü (pozitif) anlamlı orta bir ilişki bulunmuştur.

Hipotez 6: Öğrencilerin memnuniyetleri ile hizmet kalitesi algıları arasında anlamlı bir ilişki vardır.

Hipotez 6a: Öğrencilerin memnuniyetleri ile hizmet boyutu algıları arasında anlamlı bir ilişki vardır.

Hipotez 6b: Öğrencilerin memnuniyetleri ile servis boyutu algıları arasında anlamlı bir ilişki vardır. ilişki vardır.

Hipotez 6c: Öğrencilerin memnuniyetleri ile personel boyutu algıları arasında anlamlı bir

Hipotez 6d: Öğrencilerin memnuniyetleri ile heveslilik boyutu algıları arasında anlamlı bir ilişki vardır.

Hipotez 6e: Öğrencilerin memnuniyetleri ile güvenlik boyutu algıları arasında anlamlı bir ilişki vardır.

Tablo 16. Memnuniyet Hizmet Kalitesi Algısı İlişkisi

\begin{tabular}{|c|c|c|c|c|c|c|c|}
\hline \multicolumn{2}{|c|}{$\begin{array}{c}\text { Pearson Korelasyon } \\
\text { Matrisi }\end{array}$} & $\begin{array}{l}\text { Hizmet } \\
\text { Kalitesi }\end{array}$ & $\begin{array}{l}\text { Hizmet } \\
\text { Boyutu }\end{array}$ & $\begin{array}{l}\text { Servis } \\
\text { Boyutu }\end{array}$ & $\begin{array}{c}\text { Personel } \\
\text { Boyutu }\end{array}$ & $\begin{array}{c}\text { Heveslilik } \\
\text { Boyutu }\end{array}$ & $\begin{array}{c}\text { Güvenlik } \\
\text { Boyutu }\end{array}$ \\
\hline \multirow{3}{*}{ Memnuniyet } & \multirow{3}{*}{$\begin{array}{c}\text { Pearson } \\
\text { Correlation } \\
\text { Sig. (2- } \\
\text { tailed) } \\
\mathrm{N}\end{array}$} & $489^{* * *}$ & $423^{* * *}$ & $349^{* *}$ & $480^{* *}$ & $414^{* *}$ & $\mathbf{3 8 1}^{* *}$ \\
\hline & & ,000 & ,000 & ,000 & ,000 & ,000 & ,000 \\
\hline & & 424 & 424 & 424 & 424 & 424 & 424 \\
\hline
\end{tabular}

Tablo 16'ya göre öğrencilerin memnuniyetleri ile hizmet kalitesi algılamaları, hizmet boyutu, servis boyutu, personel boyutu, heveslilik boyutu ve güvenlik boyutu arasında doğru yönlü (pozitif) anlamlı zayıf, zayıf, zayıf, zayıf, zayıf ve zayıf bir ilişki bulunmuştur. 
Tablo 17: Hipotez Sonuç Tablosu

\begin{tabular}{|c|c|c|c|}
\hline HIPOTEZ & & & SONUÇ \\
\hline \multirow{5}{*}{ Hipotez 1} & Hipotez 1a & Reddedildi & \multirow{5}{*}{ Reddedildi } \\
\hline & Hipotez $1 \mathrm{~b}$ & Reddedildi & \\
\hline & Hipotez 1c & Reddedildi & \\
\hline & Hipotez 1d & Reddedildi & \\
\hline & Hipotez 1e & Reddedildi & \\
\hline Hipotez 2 & Hipotez 2 & Reddedildi & Reddedildi \\
\hline Hipotez 3 & Hipotez 3 & Kismen Kabul Edildi & Kısmen Kabul Edildi \\
\hline \multirow{5}{*}{ Hipotez 4} & Hipotez 4a & Kabul Edildi & \multirow{5}{*}{ Kabul Edildi } \\
\hline & Hipotez 4b & Kabul Edildi & \\
\hline & Hipotez 4c & Kabul Edildi & \\
\hline & Hipotez 4d & Kabul Edildi & \\
\hline & Hipotez 4e & Kabul Edildi & \\
\hline Hipotez 5 & Hipotez 5 & Kabul Edildi & Kabul Edildi \\
\hline \multirow{5}{*}{ Hipotez 6} & Hipotez 6a & Kabul Edildi & \multirow{5}{*}{ Kabul Edildi } \\
\hline & Hipotez $6 b$ & Kabul Edildi & \\
\hline & Hipotez $6 \mathrm{c}$ & Kabul Edildi & \\
\hline & Hipotez 6d & Kabul Edildi & \\
\hline & Hipotez $6 \mathrm{e}$ & Kabul Edildi & \\
\hline
\end{tabular}

Tablo 17'ye göre hipotez 1 ve alt hipotezleri Reddedilmiştir. Hipotez 2 reddedilmiştir. Hipotez 3 kısmen Kabul edilmiştir. Hipotez 4, hipotez 5, hipotez 6 ve bu hipotezlerin alt hipotezleri Kabul edilmiştir.

\section{Sonuc}

Araştırma sonuçlarına göre öğrencilerin şehirlerarası otobüs işletmelerinin hizmet kalitesi ve hizmet kalitesi boyutlarına (Hizmet, servis, personel, heveslilik ve güvenlik) yönelik algılamaları ile davranışsal niyetlerinin öğrencilerin cinsiyetlerine, yaşlarına ve öğrenim durumlarına göre anlamlı farklılık göstermediği görülmüştür. Öğrencilerin otobüs işletmelerine yönelik genel memnuniyet düzeyleri öğrencilerin yaşlarına ve öğrenim durumlarına göre istatistiksel olarak anlamlı farklılık göstermiştir. Öğrencilerin cinsiyetleri ile otobüs işletmelerine yönelik genel memnuniyet düzeyleri arasında anlamlı farklılık bulunamamıştır. Araştırma sonuçları müşterilerin demografik özellikleri ile hizmet kalitesi algısı arasındaki anlamlı farklılıkları araştıran araştırma sonuçlarına Aliçavuşoğlu ve Gürbüz, 2017; Özdipçiner ve Ceylan 2017; Uslu, 2013; Koçoğlu ve Aksoy, 2012; Seçilmiş vd., 2011, benzer sonuçlara ulaşı1mıştır. Araştırmada ayrıca hizmet kalitesi, davranışsal niyet ve müşteri memnuniyeti, arasında ilişkili olduğunu ortaya koyan araştırmalara (Dağdeviren vd., 2018; Dağdeviren vd., 2017; Özdemir ve Temizel, 2017; Yapraklı ve Ünalan, 2016; Güven ve Sarış1k, 2014, Yılmaz, 2012; Arlı, 2012; Kitapçı vd., 2011; Duman, Ayduğan ve Koçak 2007; González ve Brea, 2005, benzer sonuçlara ulaşılmıştır. Yapılan araştırmadan elde edilen sonuçlar literatürü destekler niteliktedir. Yoğun rekabet, işletmelerin müşterilerinin hizmet kalite algısını sürekli takip etmek ve buna göre düzenlemeler yapmasını gerektirmektedir. Araştırmada hizmet kalitesinin ölçümü ve hizmet kalitesinin öğrencilerin memnuniyetine ve davranışsal niyetlerine etkisi incelenmiştir. Bu araştırmada iki adet karayolu ulaştırma işletmesi örnek alınmış olup genellenebilir sonuçlara ulaşmak için daha fazla ulaştırma işletmesinin araştırmaya dahil edilmesi önerilmektedir. Ayrıca karayolu ulaştırma işletmelerinden farklı olarak havayolu, demiryolu, denizyolu ulaştırma işletmelerinde bu ölçümler uygulanıp kıyaslamalar yapılabilir. 


\section{Kaynakça}

Aliçavuşoğlu, Ç. ve Gürbüz, A. (2017). Yerel ulaşım hizmetlerinde hizmet kalite boyutlarının değerlendirilmesi. PESA Uluslararası Sosyal Araştırmalar Dergisi, 3(4), 74-86.

Altunışık, R., Coşkun, R., Bayraktaroğlu, S. ve Yıldırım, E. (2012). Sosyal Bilimlerde Araştırma Yöntemleri Spss Uygulamalı (Yedinci Baskı). Sakarya: Sakarya Yayıncılık.

Arlı, E. (2012). Yat limanı işletmeciliğinde algılanan hizmet kalitesi faktörlerinin tekrar tercih etme niyeti, tavsiye etme niyeti. Anatolia: Turizm Araştırmaları Dergisi, 23 (1), 19-32.

Can, A. (2013). Spss ile bilimsel araştırma sürecinde nicel veri analizi. Ankara: Pegem Akademi.

Çokluk, Ö., Şekercioğlu, G. ve Büyüköztürk, Ş. (2012). Sosyal bilimler için çok değişkenli istatistik spss ve lirsel uygulamalarl (İkinci Baskı). Ankara: Pegem Akademi.

Dağdeviren, A., Kara, M. ve Özdemir, H. (2018). çavundur termal konaklama tesislerinde algılanan hizmet kalitesi, müşteri memnuniyeti ve davranışsal niyetler. Journal of Social And Humanities Sciences Research (Jshsr), 5(30), 4435-4442. https://doi.org/10.26450/jshsr.916

Dağdeviren, A., Özdemir, H. ve Özdemir, S.N. (2017). Termal konaklama işletmelerinde algılanan hizmet kalitesi ve davranışsal niyet ilişkisi üzerine bir araştırma kırşehir ili örneği. Uluslararas1 Uygulamalı Sosyal Bilimler Kongresi (IASOS), 21-23 Eylül 2017 Uşak/Türkiye.

Demirel, H. S. (2014). Gölbaşı ortaögretim kurumları pansiyonlarında kalan ̈ğrencilerin hizmet kalitesi algı düzeyleri, Yüksek Lisans Tezi, Türk Hava Kurumu Üniversitesi Sosyal Bilimler Enstitüsü, Ankara.

Duman, T., Ayduğan, P. ve Koçak, G. N. (2007). Karayolu yolcu taşımacılı̆̆ı hizmetlerinde hizmet kalitesi, hizmet değeri, müşteri memnuniyeti ve müşteri sadakati ilişkileri. Dokuz Eylül Üniversitesi Sosyal Bilimler Enstitüsü Dergisi, 9 (1), 151-177.

Eleren, A., Bektaş, Ç. ve Görmüş, A.Ş. (2007). Hizmet sektöründe hizmet kalitesinin servqual yöntemi ile ölçülmesi ve hazır yemek işletmesinde bir uygulama. Finans Politika \& Ekonomik Yorumlar, 44 (514): 75-88.

González, M. E. A. ve Brea, J. A. F. (2005). An investigation of the relationship among service quality, customer satisfaction and behavioural intentions in Spanish health spas. Journal of Hospitality \& Leisure Marketing, 13(2), 67-90. https://doi.org/10.1300/j150v13n02_06

Güven, E.Ö. ve Sarışık, M. (2014). Konaklama hizmetlerinde davranışsal niyeti etkileyen hizmet kalitesi boyutları, İsletme Bilimi Dergisi, 2 (2), 21-51.

Kalaycı, Ş. (2014). Faktör analizi. Kalaycı, Ş. (Ed.). (2014). Spss uygulamalı çok değiş̧kenli istatistik teknikleri içinde (s. 321-331). Ankara: Asil Yayın Dağıtım.

Kitapçı, H., Yıldırım, A. ve Çömlek, O. (2011). Grönross modeline göre bankacılıkta hizmet kalitesinin müşteri memnuniyeti, sadakati ve davranışsal niyete etkisi, Balıkesir Üniversitesi Sosyal Bilimler Enstitüsü Dergisi, 14 (26): 177-195.

Koçoğlu, C. M. ve Aksoy, R. (2012). Hizmet kalitesinin servperf yöntemi ile ölçülmesi: Otobüs işletmeleri üzerinde bir uygulama. Akademik Bakış Dergisi, 29, 1-20.

Nakip, M. (2006). Pazarlama araştırmaları teknikler ve (spss destekli) uygulamalar (İkinci Bask1). Ankara: Seçkin Yayıncılık.

Özdemir, S.N. ve Temizel G. (2017). Termal Turizmde Ev Pansiyonculuğu Eğilimi: Kızılcahamam Örneği. Journal of Recreation and Tourism Research, 4 (4): 66-84. 
Özdipçiner, N. S. ve Ceylan, S. (2017). Şehirlerarası yolcu taşımacılı̆̆ında hizmet kalitesi ve bir $\begin{array}{llll}\text { uygulama. Social } & \text { Sciences }\end{array}$ https://doi.org/10.12739/nwsa.2017.12.2.3c0158

Seçilmiş, C., Kaşlı, M., Kılıçlar, A. ve Sarı, Y. (2011). Demiryolu hizmetlerindeki kalitenin ödenen ücret açisindan müsteri tatminine etkisi. Ege Akademik Bakış, 11(4), 573-586.

Turan, A. (2014). Kamu sektöründe hizmet kalitesi: istanbul vergi daireleri üzerinde bir uygulama. Yüksek Lisans Tezi, İstanbul Gelişim Üniversitesi Sosyal Bilimler Enstitüsü.

Ural, A. ve Kılıç, İ. (2013). Bilimsel araştırma süreci ve spss ile veri analizi (Dördüncü baskı). Ankara: Detay Yayıncıl1k

Uslu, A. (2013). ankara şehirlerarası terminal işletmesi hizmet kalitesinin servperf yöntemi ile ölçülmesi. Yeni fikir dergisi,2013 (10), 67-86.

Yapraklı, Ş. ve Ünalan, M. (2016). Karayolu yolcu taşımacılığında hizmet kalitesinin ölçülmesi ve hizmet kalitesinin müşteri sadakatine etkisi: bir uygulama. Erzincan Üniversitesi Sosyal Bilimler Enstitüsü Dergisi, 9(1), 115-130.

Yılmaz, İ. (2012). Turizm öğrencilerinin karayolu yolcu taşımacıllı̆̆ hizmetlerine yönelik algılamaları. Anatolia: Turizm Araştırmaları Dergisi, 23(1), 73-85.

Zeithaml, V., Parasuraman, A. ve Berry, L. (1996). The behavioral consequences of service quality. Journal Of Marketing, 60(2), 31-46. https://doi.org/10.2307/1251929 